\title{
Theoretical and experimental studies of effective thermal insulation in the production, storage and transportation of agricultural products
}

\author{
Mikhail Lemeshko ${ }^{1, *}$, Snanislav Maslennikov ${ }^{1}$, Sergey Bashnyak $^{2}$, and Irina Kokunko ${ }^{1}$ \\ ${ }^{1}$ Don State Technical University (branch) in Shakhty, 147, Shevchenko str., 346500, Rostov region, \\ Russia \\ ${ }^{2}$ Don state agrarian University, 24, Krivoshlykov str., 346493, village Persianovsky, Rostov region, \\ Russia
}

\begin{abstract}
The article presents the results of research on a new technology for increasing the thermal insulation properties of fences based on sandwich panels for thermal insulation of buildings, storage facilities, cooling chambers, industrial and residential premises, as well as for the production, storage and transportation of agricultural products. The costs of cold and heat are reflected in the cost of agricultural products. The idea is to replace the air in the pores of mineral (basalt) wool with gas with low thermal conductivity. The article presents a theoretical analysis of the possible effectiveness of this substitution, and the developed research methodology. The analysis made it possible to predict a possible decrease in the heat transfer coefficient by about $21 \%$. This is a very high indicator. It can be assumed that approximately this value can reduce the cost of electricity spent on maintaining rational temperatures. The scheme and description of the stand for experimental research, and the results of these studies are given. It was found that as a result of the conducted experiments, it was possible to obtain a decrease in the thermal conductivity of sandwich panels with argon by $8.8 \%$, and with carbon dioxide by $10.2 \%$.
\end{abstract}

\section{Introduction}

Thermal insulation of buildings, cooling chambers and various types of storage facilities, enterprises for processing and storage of agricultural products is of great importance, and above all, economic [1]. It is obvious that in the production of milk, meat, fish, vegetables and fruits, and other products, its cost price includes the cost of creating and maintaining a rational temperature in the zones of production, storage and transportation, as a rule, this is the cost of cooling [2,3,4]. It is very important to minimize heat flows through walls, thermal barriers and special thermal protections. New breakthrough solutions based on knowledge in the field of thermal conductivity are needed.

\footnotetext{
*Corresponding author: lem-mikhail@ya.ru
} 
Often, industrial sandwich panels are used to perform thermal insulation fences [5]. These relatively effective products for the design of heat-insulating enclosing structures include sandwich panels, wall and wall type products. It is obvious that the issue of creating sandwich panels with high thermal resistance is relevant [6]. Polyurethane foam [7] or mineral wool [8] is most often used as a thermal insulation layer in typical sandwich panels. It is these materials that determine the effectiveness of thermal insulation, primarily in terms of thermal conductivity and cost [3,9]. However, polyurethane foam (PU) is a firehazardous material and when exposed to high temperature, it decomposes into components, with the release of gases that are dangerous to health [10]. Well-known examples of fires in industrial and civil buildings, the structures of which were used in sandwich panels based on polyurethane foam. This important circumstance raises the question of whether it is appropriate to use sandwich panels based on non-flammable and safe materials, which include basalt (mineral) wool. Taking into account the relative high fire hazard of PU sandwich panels and the relatively low fire hazard of mineral wool sandwich panels, we solve the problem of reducing the thermal conductivity of mineral wool.

It is taken into account that the cost of mineral wool sandwich panels is lower than the cost of their polyurethane foam sandwich panels [11,12].

The idea of the research is to develop a sandwich panel with a relatively low coefficient of thermal conductivity based on the method of replacing air in mineral wool insulation with argon gas or carbon dioxide.

\section{Theoretical research}

It is known from publications $[13,14,15]$ that the proportion of air in mineral wool depends on its density, and for sandwich panels with a thermal insulation density of $40-60 \mathrm{~kg} / \mathrm{m} 3$ is $85-95 \%$. In further calculations, we accept $90 \%$. We use the hypothesis and assume that the heat transfer through the sandwich panel is carried out through the air and through the mineral wool fibers, i.e., through the air, the heat is transmitted in the volume of $85-95 \%$, and the heat transfer through the mineral wool fibers is $5-15 \%$. Takes into account $-10 \%$.

Given the above, the thermal conductivity coefficient of mineral wool sandwich panel is equal to: mineral wool,

$$
\lambda_{\text {mineral wool }}=0.9 \lambda_{\text {air }}+0.1 \lambda_{\text {fibers }}
$$

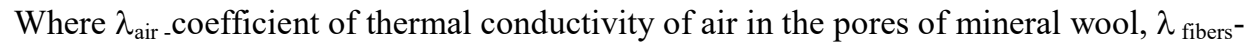
coefficient of thermal conductivity of mineral wool fibers.

Using the values of the thermal conductivity of mineral wool $\lambda$ mineral wool $=0.05 \mathrm{~W} /(\mathrm{m} *$ $\mathrm{deg}$ ), for mineral wool of relatively high density; and the thermal conductivity of air, $\lambda_{\text {air }}=$ $0.0259(\mathrm{~W} /(\mathrm{m} \bullet \mathrm{deg})$, we find the thermal conductivity of mineral wool fibers:

$$
\lambda_{\text {fibers }}=\left(\lambda_{\text {mineral wool }}-0.9 \lambda_{\text {air }}\right) / 0.1=0.267(\mathrm{~W} /(\mathrm{m} \bullet \mathrm{deg})
$$

Calculate the coefficient of thermal conductivity of mineral wool, in which the air is $100 \%$ replaced by argon gas. We use the hypothesis: "thermal Conductivity through mineral wool, in the pores of which air is replaced by argon, will be formed through two heat flows: through the fibers of mineral wool and argon gas in its pores." In fact, this is only a hypothesis that simplifies the calculation of heat transfer through the plate of a sandwich panel made of mineral wool.

Considering the physical model of the heat transfer process of a complex structure of mineral wool on the border of its contact with the enclosing sheets made of metal. For heat transfer analysis, the term "thermal bridge"is often used. This concept takes into account 
the contact of part of the fibers with the surface of the fence sheets and the contact between the fibers.

Since the thermal conductivity of the fibers themselves is relatively high- 0.267 (W / (m•deg), some of the heat will be transferred through a chain of thermal bridges. However, the applied hypothesis confirms its significance due to the fact that the share of "thermal bridges" is relatively small and therefore the thermal conductivity of mineral wool is much less than the thermal conductivity of its fibers. Let's make a calculation for replacing air with argon gas:

$$
\lambda_{\text {mineral wool_Ar }}=0.9 \lambda_{\mathrm{Ar}}+0.1 \lambda_{\text {fibers }}=0.0429(\mathrm{~W} /(\mathrm{m} \bullet \mathrm{deg})
$$

Where $\lambda$ mineral wool_Ar -is the thermal conductivity coefficient of mineral wool with $\operatorname{argon} ; \lambda_{\mathrm{Ar}}$ is the thermal conductivity coefficient of $\operatorname{argon}\left(0.018 \mathrm{~W} /(\mathrm{m} \bullet \mathrm{deg}) ; \lambda_{\text {fibers }}-\right.$ is the thermal conductivity coefficient of mineral wool fibers $(0.267 \mathrm{~W} /(\mathrm{m} \bullet \mathrm{deg})$.

Thus, the theoretical value of the thermal conductivity coefficient of mineral wool, in which the air is replaced with argon, is obtained.

We determine the theoretical value of the efficiency of the proposed method- "replacing air in a sandwich panel with argon" by a simple ratio of thermal conductivity:

$$
0.05 / 0.0429=1.166
$$

As you can see, the thermal conductivity of a sandwich panel in which air is replaced with argon is theoretically reduced by $16.6 \%$.

Next, we will calculate the thermal conductivity of mineral wool, in which air is replaced with carbon dioxide. According to the reference table [16], at a temperature of 25 ${ }^{\circ} \mathrm{C}$, the thermal conductivity of carbon dioxide is $\lambda_{\text {co2 }}=0.016(\mathrm{~W} /(\mathrm{m} \cdot \mathrm{deg})$.

Using the expression (1), we replace the air thermal conductivity coefficient with the carbon dioxide thermal conductivity coefficient:

$$
\lambda_{\text {mineral wool_co2 }}=0.9 \lambda_{\text {co2 }}+0.1 \lambda \lambda_{\text {fibers }}=0.0411(\mathrm{~W} /(\mathrm{m} \bullet \operatorname{deg})
$$

Where $\lambda_{\mathrm{co} 2}$ - coefficient of thermal conductivity of $\mathrm{CO}_{2}\left(0.016(\mathrm{~W} /(\mathrm{m} \bullet \mathrm{deg})), \lambda_{\mathrm{vo}}\right.$ coefficient of thermal conductivity of mineral wool fibers $(0.267 \mathrm{~W} /(\mathrm{m} \bullet \mathrm{deg})$.

We determine the theoretical value of the proposed method's efficiency- " replacement of air in a sandwich panel with carbon dioxide»»

$$
0.05 / 0.0411=1.216
$$

Thus, the thermal conductivity of a sandwich panel in which air is replaced with carbon dioxide is reduced by $21.6 \%$. The results of theoretical research are shown in the diagram (Fig.1). 


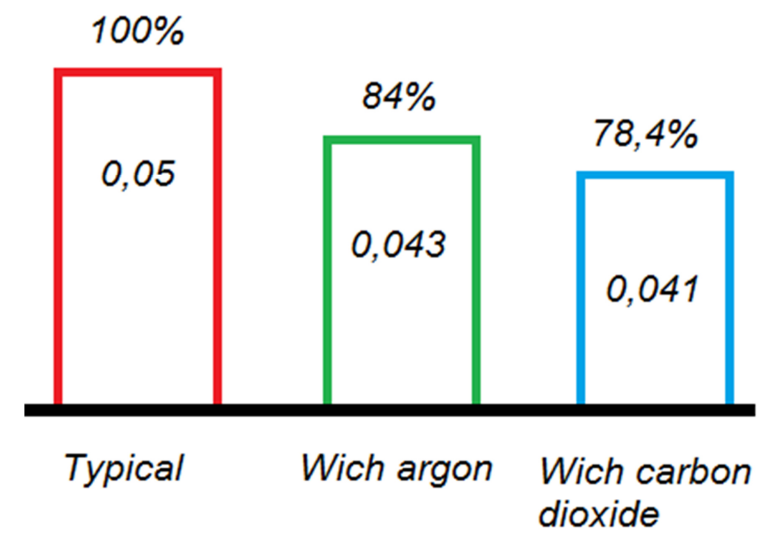

Fig. 1. Comparison Diagram of thermal conductivity of sandwich panels.

\section{Experimental studies}

The purpose of the research was to determine the effectiveness of the method for reducing the thermal conductivity of a sandwich panel by replacing air in mineral wool with argon or carbon dioxide, and to determine the actual effectiveness of the proposed method.

The objectives of the experimental studies were to verify the validity of the hypothesis for dividing the heat transfer in mineral wool into two streams - through fibers and through gas, as well as to check the theoretical prerequisites for the effectiveness of the proposed method.

A comparative test method was used for sandwich panel samples, a typical one and two experimental ones; one experimental model used argon gas, and the other experimental model used carbon dioxide. Samples of sandwich panels were used in the following sizes: $400 * 400 * 50$ all Samples intended for filling with gases are sealed with two nipples. The following method of replacing air with the gas under study was used. When the input and output nipples are open at a pressure of 2 ATI., gas was supplied from cylinders for 20 minutes. This method has not been optimized in detail. The degree of substitution of air for gas in the pores of mineral wool has not been studied.

A specialized stand was used in the research. The stand includes a heat-insulated chamber in which a constant temperature is maintained. This chamber provides temperature control in the range from 20 to $500 \mathrm{C}$. the Stand includes a refrigerator chamber made on the basis of a freezer of the "lari" type, in which it is possible to adjust the temperature inside the chamber. In the upper cover of this chamber, an opening is made in which the test samples were hermetically installed. For fig.2. shows a diagram of the stand used, which shows the elements of the stand. Sensors were used for surface temperature of typical and experimental sandwich panels, ambient air temperatures, and air from a heat gun. In this case, each sensor is duplicated, each parameter was measured by two adjusted thermocouples of the " L " type. 


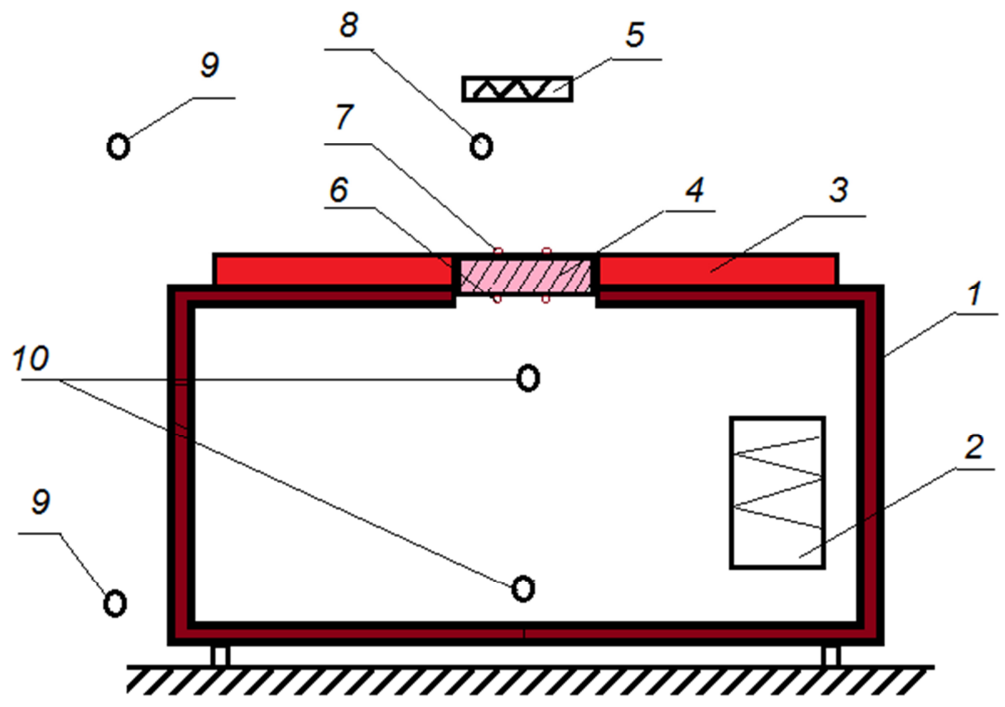

Fig. 2. Scheme of the research stand: 1-insulated housing (freezer chamber), 2 -cooling device, 3 additional insulation, 4 -test sample sandwich panel, 5-heat source, 6, 7,8,9,10 - temperature sensors.

The cooling system is shown conditionally, it does not have a fan, but includes a cold storage battery to stabilize the temperature in the chamber.

Measurements were performed with simultaneous registration of these sensors ' indicators and the ability to quickly view dependencies. the measurement results were saved as tables and as graphical temperature-time dependencies. Dependencies were fixed in electronic form to a file (Fig.3). In this case, a device was used that includes an ADC and is made on the basis of blocks of the company "Aries", with the appropriate software. The program interface allows you to configure the ranges and characteristics of graphic constructions, including the scale and color of lines on 8 channels. The device is connected to the computer via the RS 365 Protocol.

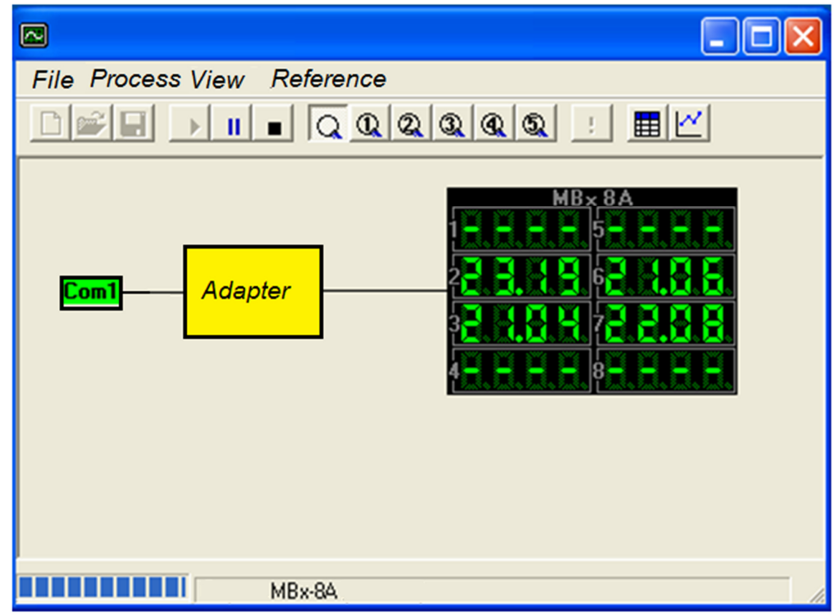

Fig. 3. Working field of the measuring device program.

In General, the thermocouples were placed at two points, duplicating each other. In the refrigerator chamber, the temperature was measured at two points, with two thermocouples, 
one of which was measured at the bottom of the chamber, and the second thermocouple was fixed in the air near the inner surface of the sandwich panel. Two thermocouples were placed on the inside of the sandwich panel under study. Two thermocouples were fixed to the surface from above on the outside of the sandwich panel under study, and two thermocouples measured the ambient air temperature.

\section{Results of experimental studies}

The data of temperature levels on the surfaces of three types of sandwich panels at different temperature pressures (differences in air temperatures outside and inside the freezer) were obtained. In this case, the base value is the surface temperatures on a typical sandwich panel, and the test values are the temperature values for the sample in which the air is replaced with argon gas and the sample in which the air is replaced with carbon dioxide.

The ratio of the temperature difference on the base sample to the temperature difference on the test sample is equal to the ratio of the thermal conductivity coefficients of the materials under study. Thus, the actual thermal conductivity coefficients of the test samples are determined.

Figure 4 shows as an example a graph of temperature measurement in experiments with the replacement of air in a sandwich panel with an inert argon gas.

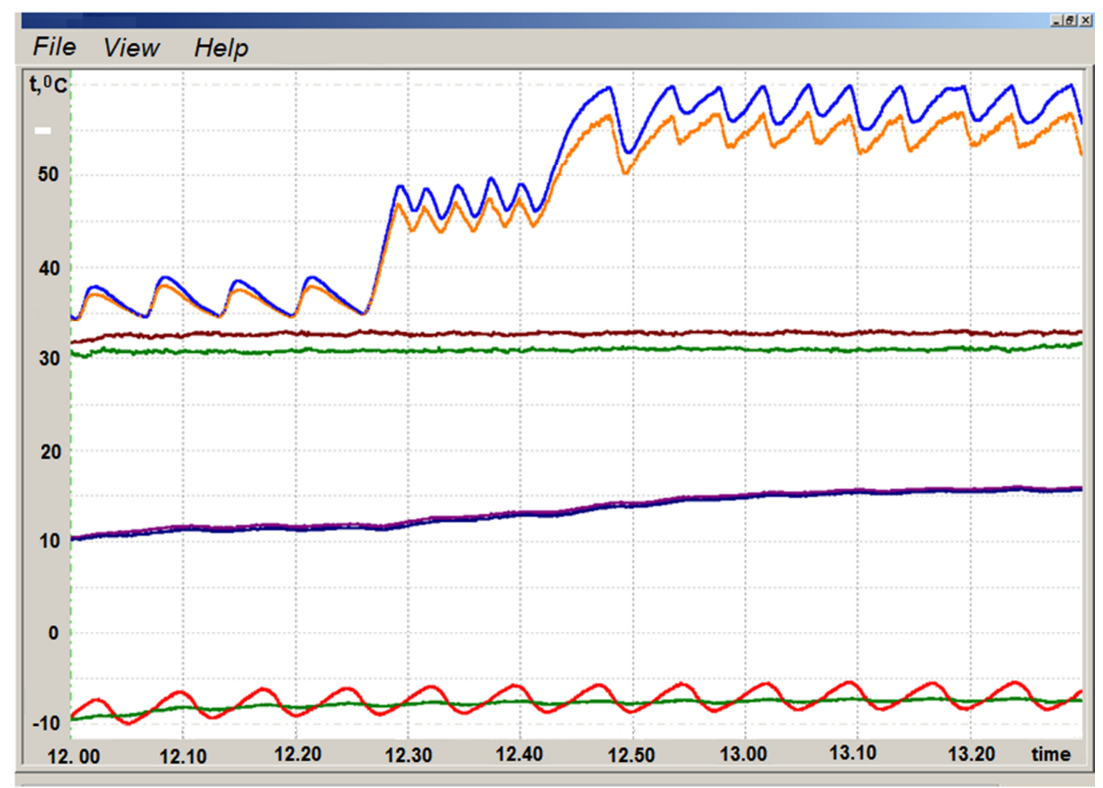

Fig. 4. Temperature change Graphs for argon-saturated sandwich panel.

On the graph, orange and blue indicate the temperatures of the two air thermocouples in the insulated chamber (bottom and top), yellow and green indicate the temperatures inside the freezer, brown and green indicate the temperatures of the outer surface of the sample, and blue indicates the temperature of the inner surface (in the freezer). As can be seen in the graph below (Fig. 5), the temperature in the heat-insulated chamber at the two points of the chamber volume changes differently. The temperature sensor located at the bottom of the chamber closer to the cold accumulator practically does not reflect the cycle of temperature fluctuations (the green line on the graph) due to the switching on and off of the cooling system compressor. 
A temperature sensor close to the inner surface of the sandwich panel sample under study reflects the dynamics of temperature changes (orange line) in this area of the inner volume of the insulated chamber. However, the average temperature values of both sensors are almost equal, the deviation is less than $2 \%$.

The generalized measurement results are presented in table 1, which shows the average values of the thermocouple readings. The obtained data allow us to calculate the heat flow for all three test samples of the experiment, taking into account information about the thermal conductivity of the basic, typical sandwich panel.

The following symbols are used in table 1. In the column"sample Type" designation of "Air" corresponds to the sample of typical sandwich panels; "Argon" corresponds to the sample with the substitution of air for argon, $\mathrm{CO}_{2}$ corresponds to a sample with replacement of air with carbon dioxide; the symbols $\mathrm{t}_{\mathrm{b} 1}, \mathrm{t}_{\mathrm{b} 2}$ - temperature hot air from the first and second sensor, respectively; $t_{\mathrm{c} 11}$ - the surface temperature of the sandwich panels from the sensor 1 , $\mathrm{tc}_{12}$ - temperature external surfaces of the sandwich panel from the sensor $2 ; t_{\mathrm{c} 21}$ temperature internal (in the camera) of the surface of a sandwich panel, from the first sensor; $t_{c 22}$ - temperature of the inner (in the chamber) surface of the sandwich panel, from the second sensor; $t_{\mathrm{vk} 1}$-air temperature in the chamber from the first sensor; $t_{\mathrm{vk} 2}$-air temperature in the chamber from the second sensor.

Table 1. Results of temperature measurements for a group of experiments.

\begin{tabular}{|c|c|c|c|c|c|c|c|c|c|}
\hline & \multirow{2}{*}{$\begin{array}{c}\text { Type } \\
\text { sample's }\end{array}$} & \multicolumn{7}{|c|}{ Panel air and surface temperatures } \\
\cline { 3 - 10 } & $\mathbf{T}_{\mathbf{b} 1}$ & $\mathbf{T}_{\mathbf{b} 2}$ & $\mathbf{t}_{\mathbf{c} 11}$ & $\mathbf{t}_{\mathbf{c} 2}$ & $\mathbf{t}_{\mathbf{c} 21}$ & $\mathbf{t}_{\mathbf{c} 22}$ & $\mathbf{t}_{\mathbf{v k} 1}$ & $\mathbf{t}_{\mathbf{v} \mathbf{2}}$ \\
\hline 1 & Air & 30 & 31 & 25 & 25.5 & 6.1 & 6.4 & 6.0 & -5.8 \\
\hline 2 & $\mathrm{~A} \Gamma$ & 30 & 32 & 26 & 26 & 5.2 & 5.1 & 6.0 & -5.3 \\
\hline 3 & $\mathrm{CO}_{2}$ & 30 & 30 & 25.5 & 26 & 5.1 & 4.8 & 6.0 & -5.3 \\
\hline 4 & $\mathrm{Air}$ & 40 & 42 & 28 & 27.8 & 6.9 & 7 & -5.8 & -5.8 \\
\hline 5 & $\mathrm{Ar}$ & 40 & 41 & 27.9 & 28.3 & 5.7 & 8 & -6.0 & -6.0 \\
\hline 6 & $\mathrm{CO}_{2}$ & 40 & 40 & 28.0 & 28.5 & 5.6 & 7 & -6.2 & -6.1 \\
\hline 7 & $\mathrm{Air}$ & 50 & 52 & 29.7 & 29.4 & 8.3 & 8 & -6.2 & -6.0 \\
\hline 8 & $\mathrm{Ar}$ & 50 & 50 & 29.8 & 29.2 & 6.6 & 7 & -6.3 & -6.0 \\
\hline 9 & $\mathrm{CO}_{2}$ & 50 & 52 & 29.9 & 29.5 & 6.2 & 6 & -6.0 & -6.0 \\
\hline
\end{tabular}

The reliability of the results and sufficiency of the experiments were determined using the student's criterion.

Based on the results of processing the results of experimental studies, the relative decrease in the thermal conductivity coefficient of experimental samples in relation to the standard sample at the studied ambient temperatures was determined.

The results of the calculations are shown below :

$30{ }^{\circ} \mathrm{C}$

$$
\begin{aligned}
\lambda \operatorname{argon} & =0.0456 ; \Delta \lambda \operatorname{argon}=(0.05-0.045) / 0.05=8 \% \\
\lambda \operatorname{co} 2 & =0.04 ; \Delta \lambda \operatorname{co} 2=(0.05-0.0465) / 0.05=10 \%
\end{aligned}
$$

$40{ }^{0} \mathrm{C}$

$$
\begin{gathered}
\lambda \operatorname{argon}=0.0465 ; \Delta \lambda \operatorname{argon}=(0.05-0.0445) / 0.05=9.0 \% \\
\lambda \operatorname{co} 2=0.0460 ; \Delta \lambda \operatorname{co} 2=(0.05-0.0469) / 0.05=10.2 \%
\end{gathered}
$$

$50{ }^{0} \mathrm{C}$

$$
\lambda \operatorname{argon}=0.0465 ; \Delta \lambda \operatorname{argon}=(0.05-0.0465) / 0.05=9.4 \%
$$




$$
\lambda \operatorname{co} 2=0.0457 ; \Delta \lambda \operatorname{co} 2=(0.05-0.0460) / 0.05=10.7 \%
$$

On average, for the studied temperature range, the decrease in the thermal conductivity coefficient was:

$$
\begin{aligned}
& \Delta \lambda \text { argon }=8.8 \% \text { (relative error } 0.1 \% \text { ) } \\
& \Delta \lambda \operatorname{co} 2=10.2 \% \text { (relative error } 0.12 \% \text { ) }
\end{aligned}
$$

\section{Conclusions}

1. It is theoretically established that when air is completely replaced with argon gas in the pores of mineral wool, its thermal conductivity decreases by $16.6 \%$; and when air is replaced with carbon dioxide, it decreases by $21.6 \%$.

2. The theoretically established efficiency of replacing air with gas with low thermal conductivity is significant for one type of density of the studied mineral wool; however, it is established that the lower the density of mineral wool, the more effective the studied substitution is.

3. It was experimentally established that it was practically possible to obtain a reduction in the thermal conductivity of experimental sandwich panels based on mineral wool, for argon by $8.8 \%$, and for carbon dioxide by $10.2 \%$.

4. The discrepancy between the theoretical and experimental data seems to be due to incomplete substitution of air for gases in the experimental samples of mineral wool with the used air replacement technology; this technology should be improved.

\section{References}

1. S.N. Ovsyannikov, T.A. Stepanova, Materials of the $V$ all-Russian scientific and practical conference with international participation "Investment and real estate as a material basis for modernization and innovative development of the economy" (Tomsk, 2015)

2. A.A. Golikova, Z.S. Nagaeva, Scientific and Technical Journal on Constraction and Architecture 14(66), 15-21 (2019)

3. F. Mark, Polyurethanes. Composition, properties, production, application (Profession, $\mathrm{SPb}, 2018)$

4. Russian Federation Standard GOST R 56590-2015 (2015)

5. J.P. Vitale, G. Francucci, A. Stocch, Journal of Sandwich Structures \& Materials (2016) DOI: 10.1177 / 1099636216635630

6. V.I. Irzhak, Topological structure of polymers (Kazan, publishing house KNITU, 2013)

7. Russian Federation Standard GOST R 56590-2015 (2015)

8. Russian Federation Standard GOST 4640-2011 (2011)

9. S.D. Grubin, M. Beaujean, Materials of the seminar "ozone-Safe technologies in the polyurethane foam sector" (Moscow, 2015)

10. A.A. Zakharchenko, M.A. Vaniev, A.B. Kochnov, The news of Volgograd state technical University 5(228), 7-18 (2019)

11. RR-0002: The Thermal Metric Project - Summary Report (Building Science Corporation, 2013) http://www.buildingscience.com/documents/special/content /thermal-metric/BSCThermalMetricSummaryReport_20131021.pdf

12. L.R. Polyurethans, A versatile specialty plastic. Sixth edition (Verlag Moderne Industrie, 2012) 
13. Russian Federation Standard GOST 31924 (2012)

14. M.A. Lemeshko, O.S. Anisimova, V.V. Sokolova, Innovative ways of development of agro-industrial complex: problems and prospects. Materials of the international scientific and practical conference 4, 62-64 (2013)

15. V.S. Melnikov, S.A. Vanin, M.V. Melnikov, Internet journal "NAUKOVEDENIE" 9, 3 (2017)

16. N.B. Vargaftik, Handbook of thermophysical properties of gases and liquids (Book on Demand, Moscow, 2012) 